\title{
Importance of the process of mass-exchange between main stream of a river and underflow for modelling of concentration of radioactive substances in river water and bed sediments
}

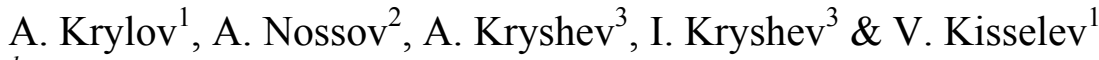 \\ ${ }^{I}$ Nuclear Safety Institute of Russian Academy of Sciences, Russia \\ ${ }^{2}$ State Enterprise "Atomenergoproeckt", Russia \\ ${ }^{3} R P A$ "Typhoon", Russia
}

\begin{abstract}
Relatively simple compartmental models of transport of radioactive substances by a uniform flow are quite often successfully used for assessment of concentrations of radionuclides in water, bottom sediments and flood plains of rivers. However, one should take into account specificity of contamination of a river to be simulated. In this work the results of modelling of ${ }^{89,90} \mathrm{Sr},{ }^{137} \mathrm{Cs}$, and ${ }^{239,240} \mathrm{Pu}$ migration in the Techa River were compared with observed data. As a result of the comparison the authors have supposed that taking into account of the process of mass exchange between the main stream of a river and underflow is important for the adequate modelling of migration and accumulation of radionuclides (and other contaminants with similar physical and chemical properties) in rivers that were polluted during a long period of time. It is known that underflow of a river can reach $30 \%$ of the main stream. The performed analysis of comparison of the modelling results with the observed data has enabled an evaluation of numerical values of parameters by means of which the interaction between the main stream and the underflow may be described. The choice of the Techa-river as an example was not casual. For more than 50 years the "Mayak" plant was fulfilling its important defense mission and discharged contaminated effluents to the Techa-river. As a result the whole river and its basin have become contaminated by long-lived radionuclides. The issues of the Techa-river contamination by radionuclides and simulation of their transport have been given attention over decades by many scientists.

Keywords: water quality modelling, radioactive contamination, Techa, Mayak.
\end{abstract}




\section{Introduction}

At present "the dam of Reservoir 11" is considered the Techa-river head. During modelling and validation of the modelling results, the observed concentrations of the radionuclides at the Musliumovo-village (the 44th $\mathrm{km}$ ), Brodokalmak-village (the 78th $\mathrm{km}$ ) and Zatechenskoye-village (the 207th $\mathrm{km}$ ) were used.

For assessment concentrations of the radionuclides in the Techa water, the two-compartmental model of a one-dimensional flow was used. The model is based on the one-dimensional turbulent-diffusion equation and takes to account the interaction between radioactive substances in the water flow (solute, sorbed on suspended particles) and those of bottom sediments [4, 16]. The following assumptions are made in the model: rate of exchange by radioactive substances between water and bottom sediments is proportional to the concentration of radionuclides in the liquid and the solid phases; the processes of sorption and desorption of radionuclides by the solid phase is considered instantaneous, equilibrium and obeying the linear isotherm with the invariable distribution coefficient; the exchange between the river bottom and the water mass proceeds within an equally-accessible upper layer of bottom sediments of ' $h$ ' thickness; the silting process may be neglected; the radioactive substances are transferred by water flow and are dispersed over the water volume due to longitudinal turbulent dispersion. The substances are distributed uniformly over the river section, and only the longitudinal component of convective dispersion is taken into account. The system of equations describing the transfer of radionuclides along the river is as follows:

$$
\left\{\begin{array}{l}
\frac{\partial\left(A C_{1}(x, t)\right)}{\partial t}+\frac{\partial}{\partial x}\left(Q C_{1}-\mathrm{D}_{\mathrm{L}} A \frac{\partial C_{1}}{\partial x}\right)=-\lambda A C_{1}-\frac{A C_{1} U \alpha_{T 1}}{H}+\frac{A C_{2} \vartheta \alpha_{T 2}}{H} \\
+\frac{A \beta}{H} *\left(\alpha_{P 2} C_{2}-\alpha_{P 1} C_{1}\right)+F(x, t) \\
\frac{\partial C_{2}(x, t)}{\partial t}=-\lambda C_{2}+\frac{C_{1} U \alpha_{T 1}}{h}-\frac{\vartheta C_{2} \alpha_{T 2}}{h}-\frac{\beta}{h}\left(\alpha_{P 2} C_{2}-\alpha_{P 1} C_{1}\right)-\frac{\gamma \alpha_{P 2} C_{2}}{h}
\end{array}\right.
$$

where: ' $\mathrm{t}$ ' is the time ( $\mathrm{s})$; ' $\mathrm{x}$ ' is the coordinate along the river channel $(\mathrm{m})$; ' $\mathrm{C}{ }_{1}$ ' and ' $\mathrm{C}_{2}$ ' are total concentrations in water and bottom sediments, respectively $\left(\mathrm{Bq} / \mathrm{m}^{3}\right)$; ' $\lambda$ ' is the radioactive decay constant $(1 / \mathrm{s})$; ' $\mathrm{A}$ ' is the river section area $\left(\mathrm{m}^{2}\right)$; " $\mathrm{H}$ " is the average depth $(\mathrm{m})$; ' $\mathrm{Q}$ ' is the flow rate of running water $\left(\mathrm{m}^{3} / \mathrm{s}\right)$; ' $\mathrm{D}_{\mathrm{L}}$ ' is the longitudinal dispersion coefficient $\left(\mathrm{m}^{2} / \mathrm{s}\right)$; ' $\mathrm{F}$ ' is the radionuclide inflow sources $\left(\mathrm{Bq} /\left(\mathrm{m}^{*} \mathrm{~s}\right)\right)$; ' $\mathrm{h}$ ' is the exchange-layer thickness $(\mathrm{m})$; ' $\beta$ ' is the coefficient of diffusive mass exchange of radionuclides between water mass and bottom sediments $(\mathrm{m} / \mathrm{s})$; ' $U$ ' is the average precipitation rate of suspended particles $(\mathrm{m} / \mathrm{s})$; ' $\alpha \alpha_{\mathrm{T} 1}$ ' is the fraction of a radionuclide sorbed by suspended particles (dimensionless unit); ' $\alpha_{\mathrm{T} 2}$ ' is the fraction of a radionuclide sorbed by the solid phase of the effective layer of bottom sediments (dimensionless unit); ' $\alpha_{\mathrm{p} 1}$ ' and ' $\alpha_{\mathrm{p} 2}$ ' are the fractions of a radionuclide being in the dissolved state in water mass and in the effective layer of bottom sediments, respectively (dimensionless units); ' $\gamma$ ' is the mass exchange coefficient of a radionuclide 
contained in interstitial water between the effective layer of bottom sediments and the bottom stratum $(\mathrm{m} / \mathrm{s})$; ' $\vartheta$ ' is a radionuclide mass exchange coefficient due to process of stirring-up (erosion) of contaminated bottom sediments $(\mathrm{m} / \mathrm{s})$.

The values of ' $\alpha_{\mathrm{T} 1}$ ', ' $\alpha_{\mathrm{T} 2}$,', ' $\alpha_{\mathrm{P} 1}$ ' and ' $\alpha_{\mathrm{P} 2}$ ' determining the radionuclide fractions sorbed and dissolved states can be found from the following expressions:

$$
\alpha_{p 1}=\frac{1}{1+S_{1} k_{d 1}}, \alpha_{p 2}=\frac{1}{1+m k_{d 2}}, \alpha_{T 1}=\frac{S_{1} k_{d 1}}{1+S_{1} k_{d 1}}, \alpha_{T 2}=\frac{m k_{d 2}}{1+m k_{d 2}} ;
$$

where: ' $\mathrm{k}_{\mathrm{d} 1}$ ' is the distribution coefficient of a radionuclide in the water-suspension system, $\mathrm{m}^{3} / \mathrm{kg}$; ' $\mathrm{k}_{\mathrm{d} 2}$ ' is the distribution coefficient of a radionuclide between interstitial water and the solid phase of the effective layer of bottom sediments, $\mathrm{m}^{3} / \mathrm{kg}$; ' $\mathrm{S} 1$ ' is water turbidity, $\mathrm{kg} / \mathrm{m}^{3}$; ' $\mathrm{m}$ ' is the volume weight of the effective layer of bottom sediments, $\mathrm{kg} / \mathrm{m}^{3}$.

Generally the system (1) can be solved only numerically. There are, however, practical situations where an analytical solution of the system (1) is possible as well. In most cases such analytical solution is only possible if some additional simplifying assumptions are made. But an analytical solution has a number of advantages. Firstly, it enables both analysis of the solution and determination of the most important parameters of the model through the inverse-problemsolution methods. In this study both numerical and analytical solutions of the system (1) were used. The analytical solution combined with the results of measurements of the radionuclides concentrations in water and bottom sediments was applied to perform the best-possible quantitative estimation of the most important parameters of the radionuclides migration through the use of statistical nonlinear-regression methods. It was done in assumption that the analytical estimation describes quite adequately real distribution of radionuclides in water and bottom sediments. Obtained values of parameters of the radionuclides migration were used as input data during numerical solution of more complex radionuclide migration problems for the Techa-river.

\section{Analytical solution}

To find an appropriate analytical solution, a steady-state problem was considered, i.e., the distribution of the radionuclides concentrations in water and bottom sediments was found throughout the river in case of the steady source of radionuclides. The following simplifying assumptions were additionally made: concentrations of radioactive substances in water and bottom sediments at any considered point of the river is steady; channel data are invariable throughout the river. The total flow of lateral tributaries is negligibly low as compared to that of the main river flow. The flow of river water from the head to the mouth is monotone increasing according to the linear law; radionuclide inflow from the river basin is negligibly low compared to the main contamination source located by convention at a "zero point" (at ' $\mathrm{x}=0$ '); the channel cross-section is assumed to be rectangular. In case of invariable cross-section area ' $A$ ' the dependence of water flow along the river channel is: 


$$
Q(x)=A^{*} V(x)=A(a+b x),
$$

where: ' $V(x)$ ' is the dependence of the average flow velocity on distance, $\mathrm{m} / \mathrm{s}$; ' $\mathrm{a}$ ' and ' $b$ ' are the parameters of the linear function. If there are no additional sources of radionuclides along the river and longitudinal dispersion coefficient is constant, the system (1), taking into account eqn (3), may be written as follows:

$$
\left\{\begin{array}{l}
\mathrm{D}_{\mathrm{L}} \frac{\partial^{2} C_{1}}{\partial x^{2}}-V \frac{\partial C_{1}}{\partial x}-\lambda_{1} C_{1}+\lambda_{12} C_{2}=0 \\
\lambda_{21} C_{1}-\lambda_{2} C_{2}=0
\end{array}\right.
$$

where: ' $\lambda_{1}$ ', ' $\lambda_{2}$ ', ' $\lambda_{12}$ ', ' $\lambda_{21}$, are the transfer constants describing the processes of interaction within the 'water mass - river bottom' system taking account of decay, day ${ }^{-1}$. The expressions for ' $\lambda_{1}$ ', ' $\lambda_{2}$ ', ' $\lambda_{12}$ ' and ' $\lambda_{21}$ ' are as follows:

$$
\begin{gathered}
\lambda_{1}=\lambda+\frac{U \alpha_{T 1}}{H}+\frac{\beta \alpha_{P 1}}{H}+b, \lambda_{2}=\lambda+\frac{\alpha_{T 2} \vartheta}{h}+\frac{\beta \alpha_{p 2}}{h}+\frac{\gamma \alpha_{p 2}}{h}, \\
\lambda_{12}=\frac{\beta \alpha_{p 2}}{H}+\frac{\vartheta \alpha_{T 2}}{H}, \lambda_{21}=\frac{\beta \alpha_{p 1}}{h}+\frac{U \alpha_{T 1}}{h}
\end{gathered}
$$

Finally the differential equation describing the radionuclides migration along the river in case of steady discharge rate may be written as follows:

$$
D_{L} \frac{d^{2} C_{1}}{d x^{2}}-V(x) \frac{d C_{1}}{d x}-k C_{1}=0
$$

where: ' $k$ ' is the coefficient taking into account of the processes of interaction between the water mass and the river bottom, as well as the decay process, day ${ }^{-1}$. In steady state its value is determined by the formula:

$$
k=\left(\lambda_{1}-\frac{\lambda_{12} \lambda_{21}}{\lambda_{2}}\right)
$$

For minor rivers or in cases of considerable distances between the discharge point and the studied river sections, the longitudinal dispersion may be neglected. For such cases the equation (6) is further simplified:

$$
-V(x) \frac{d C_{1}}{d x}-k C_{1}=0
$$

The boundary conditions for the (8) may be written as follows:

$$
\text { at } \mathrm{x}=0, \mathrm{C}_{1}=\mathrm{C}_{0}=\mathrm{R}_{0} / \mathrm{Q} \text {, }
$$

where: ' $\mathrm{R}_{0}$ ' is the discharge rate of a steady source, $\mathrm{Bq} / \mathrm{s}$; and ' $\mathrm{Q}$ ' is the water flow in the river, $\mathrm{m}^{3} / \mathrm{s}$.

From the eqn (3) the flow velocity is determined via the linear function:

$$
V(x)=(a+b x)
$$

Taking account eqn (10) and initial conditions (9), the solution of eqn (8) can be written as follows:

$$
C_{1}(x)=\frac{C_{0}(a+b x)^{\left(-\frac{k}{b}\right)}}{a^{\left(-\frac{k}{b}\right)}}, \mathrm{Bq} / \mathrm{m}^{3}
$$

The radionuclide concentration in bottom sediments may be determined from the system of equations (4): 


$$
\mathrm{C}_{2}(\mathrm{x})=\frac{\lambda_{21} \mathrm{C}_{1}(\mathrm{x})}{\lambda_{1}}, \mathrm{~Bq} / \mathrm{m}^{3}
$$

In real practice radionuclide concentraitons in bottom sediments are measured in $\mathrm{Bq} / \mathrm{kg}$ of dry weight, i.e. of the solid phase, thus the calculation of radionuclide concentrations in bottom sediments is performed using the formula:

$$
C_{2}(x)=\frac{\lambda_{21} \cdot \alpha_{T 2}}{\lambda_{2} \cdot m} C_{1}(x), \quad \mathrm{Bq} / \mathrm{kg}
$$

where ' $\alpha_{T 2}$ ' and ' $m$ ' are determined in the comments to eqn (2).

The function (11) describing analytical solution of the problem was used for statistical assessment of its parameters ' $\mathrm{C}_{0}$ ' and ' $\mathrm{k}$ ' using the observed data of radioactive substances concentrations in water (Table 1). The methods of multifactor nonlinear-regression were used. The results of the assessment one can see in Table 2.

From the eqn (9) it follows that the initial concentration of ' $C_{0}$ ' at the point ' $x$ $=0$ ' depends on the source of a radionuclide discharge to the river. According to eqn (7), the coefficient ' $k$ ' describes the radionuclide exchange rate between the main river flow and its bottom as well as the decay process.

In the considered model the numerical value of ' $\mathrm{k}$ ' coefficient may be calculated from eqns $(5,7)$. For this purpose the values of the parameters given in Tables 3 and 4 were used. One should mention that the used values of the parameters are typical for the considered radioactive substances and were successfully used in the models of transfer of radionuclides in rivers, lakes and ponds $[2,5,10]$. Comparison of the values of ' $\mathrm{k}$ ' obtained from observed data (Table 2) with values calculated by the formulas $(5,7)$ one can see in Table 5 .

Table 1: Observed concentr. of radionuclides the Techa-river $[6-8,11,13$, $15]$.

\begin{tabular}{|c|c|c|c|c|c|c|}
\hline \multirow{2}{*}{$\begin{array}{c}\mathrm{x}, \mathrm{km} \text { (from } \\
\text { the river head) }\end{array}$} & \multicolumn{2}{|c|}{${ }^{239,240} \mathrm{Pu}$} & \multicolumn{2}{c|}{${ }^{89,90} \mathrm{Sr}$} & \multicolumn{2}{c|}{${ }^{137} \mathrm{Cs}$} \\
\cline { 2 - 7 } & $\begin{array}{c}\text { water, } \\
\mathrm{Bq} / \mathrm{m}^{3}\end{array}$ & $\begin{array}{c}\text { bottom, } \\
\mathrm{Bq} / \mathrm{kg}\end{array}$ & $\begin{array}{c}\text { water, } \\
\mathrm{Bq} / \mathrm{m}^{3}\end{array}$ & $\begin{array}{c}\text { bottom, } \\
\mathrm{Bq} / \mathrm{kg}\end{array}$ & $\begin{array}{c}\text { water, } \\
\mathrm{Bq} / \mathrm{m}^{3}\end{array}$ & $\begin{array}{c}\text { bottom, } \\
\mathrm{Bq} / \mathrm{kg}\end{array}$ \\
\hline 44 & 0.25 & 40 & 18000 & 670 & 430 & 49000 \\
\hline 78 & 0.13 & 16.6 & 14000 & - & 310 & - \\
\hline 143 & 0.092 & 1.04 & 11000 & 150 & 120 & 590 \\
\hline 207 & 0.055 & 0.43 & 8000 & 200 & 70 & 200 \\
\hline
\end{tabular}

Table 2: Assessment of the values of ' $\mathrm{C}_{0}$ ' and ' $\mathrm{k}$ ' for ${ }^{90} \mathrm{Sr},{ }^{137} \mathrm{Cs}$ and ${ }^{239,240} \mathrm{Pu}$.

\begin{tabular}{|c|c|c|c|c|}
\hline \multirow{2}{*}{ Radionuclide } & \multicolumn{2}{|c|}{$\mathrm{C}_{0}$} & \multicolumn{2}{c|}{$\mathrm{k}$} \\
\cline { 2 - 5 } & Value & Standard error & Value & Standard \\
\hline${ }^{239,240} \mathrm{Pu}$ & 0.5214 & 0.1 & $1.563 * 10^{-6}$ & $2.77^{*} 10^{-7}$ \\
\hline${ }^{137} \mathrm{Cs}$ & 1004 & 156.88 & $1.65^{*} 10^{-6}$ & $2.3 * 10^{-7}$ \\
\hline${ }^{90} \mathrm{Sr}$ & 25926 & 1236 & $7.52^{*} 10^{-7}$ & $5.54 * 10^{-8}$ \\
\hline
\end{tabular}


Table 3: $\quad$ Distribution coefficients.

\begin{tabular}{|l|l|l|l|l|l|l|}
\hline $\begin{array}{l}\text { Distribution coefficients, } \\
\left(\mathrm{m}^{3} / \mathrm{kg}\right)\end{array}$ & \multicolumn{5}{|l|}{ Analytical model } & \multicolumn{3}{l|}{ Numerical model } \\
\hline $\begin{array}{l}\text { Between water and } \\
\text { suspension }\end{array}$ & 0.03 & 10.0 & 15.0 & 0.03 & $3.21-27$ & $11.2-15$ \\
\hline $\begin{array}{l}\text { Between interstitial water } \\
\text { and solid phase of bottom } \\
\text { sediments }\end{array}$ & 0.01 & 5.0 & 7.5 & 0.01 & $1.61-13$ & $5.6-7.5$ \\
\hline
\end{tabular}

* - in the course of numerical solution of the initial system of equations (1) the value of parameter was varied along the river based on available observed data.

Table 4: $\quad$ Parameters of the models.

\begin{tabular}{|c|c|c|}
\hline Parameter & Analytical & Numerical \\
\hline River width*, $\mathrm{m}$ & 21.0 & 21.0 to 32.0 \\
\hline Volume mass of bottom sediments, $\mathrm{kg} / \mathrm{m}^{3}$ & 1000 & 1000 \\
\hline $\begin{array}{l}\text { Average depth of the exchange layer of bottom } \\
\text { sediments, } m\end{array}$ & 0.05 & 0.05 \\
\hline Water turbidity, $\mathrm{kg} / \mathrm{m}^{3}$ & 0.039 & 0.039 \\
\hline $\begin{array}{l}\text { Precipitation rate for susp. particles of typical size } \\
(0.05 \mathrm{~mm}), \mathrm{m} / \mathrm{s}\end{array}$ & $10^{-3}$ & $10^{-3}$ \\
\hline Mass-exchange rate, $\mathrm{m} / \mathrm{s}$ & $1.9 * 10^{-8}$ & $1.9 * 10^{-8}$ \\
\hline Stirring-up rate, $\mathrm{m} / \mathrm{s}$ & $3.9 * 10^{-8}$ & $3.9^{*} 10^{-8}$ \\
\hline $\begin{array}{l}\text { Radionuclide mass exchange coeff. between the } \\
\text { effective bottom-sediment layer and the bottom } \\
\text { stratum, } \mathrm{m} / \mathrm{s}\end{array}$ & $1.9 * 10^{-8}$ & $1.9 * 10^{-8}$ \\
\hline Water flow, $\mathrm{m}^{3} / \mathrm{s}$ & - & $2.23-4.765$ \\
\hline Water flow at the 44 th $\mathrm{km}$ from the river head, $\mathrm{m}^{3} / \mathrm{s}$ & 2.23 & 2.23 \\
\hline Maximum water flow along the river, $\mathrm{m}^{3} / \mathrm{s}$ & 4.765 & 4.765 \\
\hline
\end{tabular}

Table 5: Comparison of the values of ' $k$ ' parameter estimated on the base of the observed data with the values calculated by the formulas $(5,7)$.

\begin{tabular}{|l|l|l|}
\hline Radionuclide & $\begin{array}{l}\text { Value of ' } \mathrm{k}_{\mathrm{e}} \text { ' estimated on the } \\
\text { base of the observed data }\end{array}$ & $\begin{array}{l}\text { Value of ' } \mathrm{k}_{\mathrm{m}} \text { ' determined } \\
\text { through the formulas }(5,7)\end{array}$ \\
\hline${ }^{239,240} \mathrm{Pu}$ & $1.563^{*} 10^{-6}$ & $7.65^{*} 10^{-7}$ \\
\hline${ }^{137} \mathrm{Cs}$ & $1.65 * 10^{-6}$ & $1.03^{*} 10^{-6}$ \\
\hline${ }^{90} \mathrm{Sr}$ & $7.52 * 10^{-7}$ & $7.95^{*} 10^{-7}$ \\
\hline
\end{tabular}

According to the data of Table 5, the value of ' $\mathrm{k}_{\mathrm{e}}$ ' for ${ }^{90} \mathrm{Sr}$ estimated on the base of the observed data is slightly below that of ' $\mathrm{k}_{\mathrm{m}}$ ' calculated by the formulas $(5,7)$. The discrepancy is less then $6 \%$. The authors suppose that in fact ' $\mathrm{k}_{\mathrm{e}}$ '= ' $\mathrm{k}_{\mathrm{m}}$ ', and the discrepancy is due to errors of measurements and data processing. For ${ }^{137} \mathrm{Cs}$ and ${ }^{239,240} \mathrm{Pu}$ ' $\mathrm{k}_{\mathrm{e}}$ ' is considerably larger (by more than 1.5 and 2 times, 
respectively) than ' $\mathrm{k}_{\mathrm{m}}$ '. This is an indirect indication on the lack in the system of equations (1) of an essential, for these radionuclides, process influencing their exchange between the main river flow and the river bottom. The authors have set up the hypothesis that the process is the exchange of contaminants between the main river flow and its underflow. At the qualitative level the following explanation may be proposed: ${ }^{90} \mathrm{Sr}$ has a considerably larger mobility than ${ }^{137} \mathrm{Cs}$ and ${ }^{239,240} \mathrm{Pu}$. Thus it may be suggested that the discharge of ${ }^{90} \mathrm{Sr}$ to the Techariver over the many years have resulted in a considerably larger contamination of the river underflow and the banks of the river by ${ }^{90} \mathrm{Sr}$, as compared to ${ }^{137} \mathrm{Cs}$ and ${ }^{239,240} \mathrm{Pu}$. In case of invariable discharge of contaminants the importance of the river underflow for the exchange processes would be as big as the difference between the concentrations of the contaminants in water of the underflow and in the main stream. This hypothesis gives sufficiently good explanation of the behavior of the radionuclides in the Techa-river. In case of close values of concentration of ${ }^{90} \mathrm{Sr}$ in water of the main stream and the underflow the influence of the interaction between these two flows on the concentration of ${ }^{90} \mathrm{Sr}$ in river water would be very small. For ${ }^{137} \mathrm{Cs}$ and ${ }^{239,240} \mathrm{Pu}$ the transfer process to the underflow is essential and should be taken into account in the course of modelling.

Table 6: Comparison of the calculated data and the observed data of the radionuclides concentrations $\left(\mathrm{Bq} / \mathrm{m}^{3}\right)$ in water of the Techa-river.

\begin{tabular}{|l|l|l|l|l|l|l|l|l|l|}
\hline \multirow{2}{*}{$\begin{array}{l}\text { Km from } \\
\text { the river } \\
\text { head }\end{array}$} & \multicolumn{4}{|l|}{ Observations } & \multicolumn{4}{|l|}{$\begin{array}{l}\text { Calculation, the mass } \\
\text { exchange is neglected }\end{array}$} & \multicolumn{2}{l}{$\begin{array}{l}\text { Calculation, the mass } \\
\text { exchange is taken } \\
\text { into account }\end{array}$} \\
\cline { 2 - 11 } & $\mathrm{Pu}$ & $\mathrm{Sr}$ & $\mathrm{Cs}$ & $\mathrm{Pu}$ & $\mathrm{Sr}$ & $\mathrm{Cs}$ & $\mathrm{Pu}$ & $\mathrm{Sr}$ & $\mathrm{Cs}$ \\
\hline 78 & 0.13 & 14000 & 310 & 0.21 & 15200 & 318 & 0.16 & 13200 & 283 \\
\hline 143 & 0.092 & 11000 & 120 & 0.162 & 11675 & 211 & 0.08 & 8154 & 149 \\
\hline 207 & 0.055 & 8000 & 70 & 0.12 & 8637 & 149 & 0.04 & 5000 & 80 \\
\hline
\end{tabular}

Table 7: $\quad$ Relative root-mean-square deviations of the simulation results from observed concentrations of the radionuclides in water.

\begin{tabular}{|l|l|l|}
\hline & Mass exchange is neglected & $\begin{array}{l}\text { Mass exchange is taken into } \\
\text { account }\end{array}$ \\
\hline${ }^{239,240} \mathrm{Pu}$ & $88.8 \%$ & $21.6 \%$ \\
\hline${ }^{137} \mathrm{Cs}$ & $78.5 \%$ & $16.8 \%$ \\
\hline${ }^{90} \mathrm{Sr}$ & $7.6 \%$ & $26.5 \%$ \\
\hline
\end{tabular}

Let's add to the first equation of the system (1) a new term to take into account the processes of a radionuclide interaction between the main stream of a river and the underflow. This term will elementarily and simplistically describe the exchange of dissolved radionuclides. Let's assume that the process may be described by the first-order reaction with invariable mass-exchange coefficient. In this case the system of equations (1) may be written as follows: 


$$
\left\{\begin{array}{l}
\frac{\partial\left(A C_{1}(x, t)\right)}{\partial t}+\frac{\partial}{\partial x}\left(Q C_{1}-\mathrm{D}_{\mathrm{L}} A \frac{\partial C_{1}}{\partial x}\right)=-\lambda A C_{1}-\frac{A C_{1} U \alpha_{T 1}}{H}+\frac{A C_{2} \vartheta \alpha_{T 2}}{H} \\
+\frac{A \beta}{H} *\left(\alpha_{P 2} C_{2}-\alpha_{P 1} C_{1}\right)-\frac{A \xi \alpha_{P 1} C_{1}}{H}+F(x, t) \\
\frac{\partial C_{2}(x, t)}{\partial t}=-\lambda C_{2}+\frac{C_{1} U \alpha_{T 1}}{h}-\frac{\vartheta C_{2} \alpha_{T 2}}{h}-\frac{\beta}{h}\left(\alpha_{P 2} C_{2}-\alpha_{P 1} C_{1}\right)-\frac{\gamma \alpha_{P 2} C_{2}}{h}
\end{array}\right.
$$

where: ' $\zeta$ ' is the mass-exchange coefficient of dissolved-in-water radionuclides between the main stream and the underflow, $\mathrm{m} / \mathrm{s}$.

Thus the expression (5) for ' $\lambda_{1}$ ' should be written as follows:

$$
\lambda_{1}=\lambda+\frac{U \alpha_{T 1}}{H}+\frac{\beta \alpha_{P 1}}{H}+\frac{\xi \alpha_{P 1}}{H}+b
$$

When analyzing the ratio between $\mathrm{k}_{\mathrm{e}}$ and $\mathrm{k}_{\mathrm{m}}$ (Table 5) from the standpoint of the hypothesis made, it may be suggested that the difference between $\mathrm{k}_{\mathrm{e}}$ and $\mathrm{k}_{\mathrm{m}}$ reflects the influence of the sought exchange process. Thus taking account of eqns (7) and (15), the formula for determining the sought mass-exchange coefficient ' $\zeta$ ' is written as follows:

$$
\xi=\left(k_{\ni}-k_{M}\right) * H / \alpha_{P 1},
$$

where: ' $H$ ' and ' $\alpha_{p l}$ ' are determined in the comments to the system of equations (1). According to eqn (16), the values of the mass-exchange coefficient ' $\zeta$ ' are: for ${ }^{137} \mathrm{Cs}-8.6 \cdot 10^{-7} \mathrm{~m} / \mathrm{s}$ and for ${ }^{239,240} \mathrm{Pu}-1.3 \cdot 10^{-6} \mathrm{~m} / \mathrm{s}$; for ${ }^{90} \mathrm{Sr}$ the difference turned out to be negative. Thus it may be formally suggested that this radioactive substance comes to the main stream from the more contaminated river underflow. Because no observed data on contamination of the Techa River underflow is presently available, and taking into account that the discrepancy between $\mathrm{k}_{\mathrm{e}}$ and $\mathrm{k}_{\mathrm{m}}$ for ${ }^{90} \mathrm{Sr}$ is less than $6 \%$, authors suggest that such a difference is due to errors of measurements and processing of the results; thus the value of ' $\zeta$ ' for this radionuclide is taken equal to zero.

\section{The validation of the hypothesis}

The validation of the hypothesis made was done via comparison of the results of numerical simulation taking and not taking into account of the mass-exchange between the main stream and the underflow. The calculations were performed for the part of the Techa-river between the 44 th $\mathrm{km}$ and the $207 \mathrm{th} \mathrm{km}$. The observed data on water contamination at the 44 th $\mathrm{km}$ were used as data input. One can see that the observed concentrations of radionuclides in water at the 44th $\mathrm{km}$ are in a good agreement with those calculated through the formula (11) if the values of ' $\mathrm{C}_{0}$ ' and ' $\mathrm{k}$ ' from Table 2 are used (the discrepancy varies within $0.74-4 \%$ ).

Numerical simulation of the concentrations of radioactive substances in water and bottom sediments of the Techa-river was performed by the "Kassandra" information-simulation system [16] enabling numerical solution of the system of equations (1) with no additional simplifying assumptions. "Kassandra" enables calculations with parameters varied along a river channel. Thus, in course of numerical calculations - as distinct from analytical ones - variable channel data, 
water flow and distribution coefficients (water - suspension and interstitial water - bottom sediments) were used for ${ }^{137} \mathrm{Cs}$ and ${ }^{239,240} \mathrm{Pu}$. The input parameters used in course of modelling one can find in Tables 3 and 4. The results of calculation in case of no account of the exchange with the river underflow are quoted in Tables 6 and 7. Note that for ${ }^{90} \mathrm{Sr}$ the agreement between the results of simulation and the measured values are worse at ' $\zeta>0$ ' than at ' $\zeta=0$ ' and is worsening steadily with an increase of ' $\zeta$ '.

The mass exchange with the river underflow may lead either to a radionuclide withdrawal from the main stream or to its secondary contamination $(\zeta<0)$. This means that if the concentration of a contaminant in the river underflow is higher than that of the main stream, it may be a source of contamination of the main stream. This issue, however, has not been studied is this paper. For ${ }^{90} \mathrm{Sr}$ the calculations taking into account of the mass exchange were performed at $\zeta=5^{*} 10^{-7} \mathrm{~m} / \mathrm{s}$. The results of calculations of concentrations of ${ }^{239,240} \mathrm{Pu}$ and ${ }^{137} \mathrm{Cs}$ in water of the Techa River mach better correspond with the observed data if the mass exchange between the main stream and the river underflow is taken into accounted.

\section{Conclusions}

The performed comparison of the results of simulation of migration of radioactive substances in the Techa River with the observed data has demonstrated that taking into account of the mass exchange of radionuclides between the main stream and the underflow is rather important for river contamination models. It is difficult to achieve the results of simulation corresponding with the observed data while neglecting the interaction between the two flows. In the authors' opinion, a due account of the mass exchange of radioactive substances between the main stream and the underflow is especially important for models of long enough rivers and rivers that were affected by persistent radioactive discharges during long time. Incorporation of the mentioned process into the model decreased the relative root-mean-square deviation of the calculated results from the observed data for ${ }^{137} \mathrm{Cs}$ by a factor of 4.7 and for ${ }^{239,240} \mathrm{Pu}$ by a factor of 4.1 (Table 7).

To validate the hypothesis explaining the mechanism of interaction between the main stream and the river underflow for considered radionuclides, field measurements of main hydrological parameters and contamination of the Techa River underflow are likely required. Such measurements will enable more precise definition of the mass-exchange coefficients ' $\zeta$ ' obtained through calculations $\left(1.563 * 10^{-6} \mathrm{~m} / \mathrm{s}\right.$ for ${ }^{239,240} \mathrm{Pu}$ and $8.62 * 10^{-7}$ for $\left.{ }^{137} \mathrm{Cs}\right)$. The importance of field measurements of contamination of the Techa River underflow stipulated by a possibility of the contamination of the main stream of the river by mobile radionuclides $\left({ }^{90} \mathrm{Sr}\right.$ and $\left.{ }^{3} \mathrm{H}\right)$ that could be transferred with contaminated underground waters of the suspended-water zone from the site of PA "Mayak" to long distances.

Possible secondary contamination of the main stream of the river by the contaminated river underflow requires a special research. 
The authors intend to develop in the future a model enabling a more accurate account of the exchange process with the underflow by incorporation of third "compartment" into the used "two-compartmental" model in addition to the used "water" and "bottom sediments" compartments. It will be done by addition into the system (1) of an equation describing changes in a radionuclide concentration in the river underflow.

In the authors' opinion, all considered aspects of simulation of radioactive substances in rivers may be generalized in the future to chemical pollutants with similar physical and chemical properties, such as heavy metals, phenols, etc.

\section{Acknowledgement}

This work has been done with the aid of ISTC grant 2558.

\section{References}

[1] Apolov, B. A. Doctrine of rivers, Publishing House of Moscow State University: Moscow, 1963 (in Russian).

[2] Bobrovitskaya, N., Denison, F., Nosov, A., et al., Operational models. Deliverable report for project ERB IC 15-CT98-0219 in the EC's Copernicus Programme, ed. J. Brown, NRPA, 2001.

[3] Borzilov V. A., Sedunov Yu. S., Novitskii M. A., et al., Prediction of the secondary radioactive contamination of rivers of $30-\mathrm{km}$ the zone of Chernobyl NPP, Meteorology and Hydrology, 2, 1989 (in Russian)

[4] Kononovich A. L., Nosov A. V., Longitudinal Transport of Harmful Impurities by River Flow, Atomic Energy 90(1), 2001.

[5] Kryshev, A. I., Nosov, A. V., Radioecological model of transfer of ${ }^{90} \mathrm{Sr}$ и ${ }^{137} \mathrm{Cs}$ in the river system «Iset-Tobol-Irtysh». Proceedings of Universities. Nuclear Energy, 3, pp. 16-25, 2005. (in Russian).

[6] Kryshev, I. I., Kryshev, A. I., Nosov, A. V. and Badalyan, K. D., Modelling of plutonium transfer into the Techa River. Proc. of the International Conference RADLEG-RADINFO, Moscow, 2005.

[7] Kryshev, I. I., Romanov, G. N., Chumichev, et al. Radioecological consequences of radioactive discharges into the Techa River on the Southern Urals, J. Environ. Radioactivity 38(2), pp.195-209.

[8] Makhon'ko, K. P. (ed.). The Radiation Situation in the Territory of Russia and Contiguous States in 1992-1996, Yearbooks, RPA "Typhoon": Obninsk, 1993-1998 (in Russian).

[9] Mokrov, Yu. G. Reconstruction and prognosis of the Techa River Radioactive Contamination, Part 1, Ozersk, 2002. (in Russian)

[10] Nosov A. V. Use of a Two-Dimensional Stationary Radionuclide Migration Model for Predicting the Cs-137 Content in the Yenisei River System. Atomic Energy, 93(2), 2002.

[11] Oughton, D. H., Fifield, L.K., et al. Plutonium from Mayak: Measurement of isotope ratios and activities using accelerator mass spectrometry. Environmental Science and Technology, 34, pp. 1938-1945, 2000. 
[12] Safety Series No. 50-SG-S6: Hydrological Dispersion of Radioactive Material in Relation to Nuclear Power Plant Siting, 1985.

[13] Skipperud, L., Mokrov, Yu., et al. Plutonium contamination in soils and sediments at Mayak PA, Russia. Health Physics, 89(3), pp. 255-266, 2005 .

[14] P. Strand, Yu. Mokrov, D. Oughton, et al. Biogeochemical behaviour of ${ }^{137} \mathrm{Cs}$ and ${ }^{90} \mathrm{Sr}$ in the artifical reservoirs of Mayak PA, Russia. The Science of the Total Environment, 241, pp. 107-116, 1999.

[15] Trapeznikov, A. V., Pozolotina, V.N., et al. Radioactive Contamination of the Techa River, the Urals. Health Physics, 65, pp.481-488, 1993.

[16] Kisselev, V., Krylov, A., Nosov, A., et al. Computer modelling of consequences of radioactive substances into surface water objects. Proceedings of the Academy of Sciences, Energy, 3, - pp. 74-81, 2004. 